\title{
An Integral extension of causal layered analysis
}

\author{
Chris Riedy ${ }^{\mathrm{a}}$ \\ a Institute for Sustainable Futures, University of Technology, Sydney, \\ Postal: PO Box 123 Broadway NSW 2007 Australia. \\ Tel: +61 29514 4964. Fax: +61 295144941. \\ Email: criedy@uts.edu.au
}

\begin{abstract}
Causal layered analysis (CLA) is a futures method developed by Sohail Inayatullah and since applied by numerous futurists across multiple content areas. The central assumption of CLA is that there are different levels of reality and ways of knowing; beneath the popular conceptions of an issue (the litany) and more academic analysis of systemic causes are deep worldview commitments, discourses, myths and metaphors. This layered understanding of reality initially seems to resonate with ideas from Ken Wilber's Integral Theory, which identifies developmental levels across behavioural, social, psychological and cultural quadrants. On closer inspection, there are some important theoretical and conceptual differences between CLA and Integral Theory; from an Integral perspective, the layers in CLA confuse quadrants, developmental levels and developmental lines. In this paper, I explore these differences in search of a resolution that will allow the fruitful application of CLA within an Integral Futures framework. I find that CLA, as currently conceived, is not an Integral method in its own right. However, CLA has great value for Integral Futures work as a way of drawing attention to the neglected cultural dimension of futures. Further, with some modifications and extensions, a more Integral application of CLA seems possible.
\end{abstract}

\section{Introduction}

Over the last two decades, futurists have become more aware of the roles that subjectivity, interpretation and cultural context play in shaping the way we understand and create the future. Instead of attempting to predict the future, many futurists now apply methods that are sensitive to multiple ways of knowing, recognise multiple values and seek to expose deep worldview commitments [1, 2]. Two futurists that have been at the forefront of this shift in futures theory and practice are Richard Slaughter and Sohail Inayatullah.

In his 1982 doctoral thesis, Slaughter [3] was one of the first to propose a critical approach to futures work that engaged with the inner world of subjectivity and attended to the social construction of reality. He has since become the pre-eminent advocate of Integral Futures work [2, 4, 5, 6, 7]. Integral Futures work draws on Ken Wilber's Integral Theory $[8,9,10]$, which provides a framework for honouring and integrating multiple ways of knowing. Integral Futures work seeks to include behavioural, systemic, psychological and cultural perspectives on the future, within a developmental framework. It adopts an approach called integral methodological pluralism (IMP) as a way of integrating multiple epistemologies and methods in the quest for a more comprehensive and inclusive understanding of future developments. 
Like Slaughter, Inayatullah draws attention to the multiple epistemological frameworks employed in futures work and seeks a plural approach in which there is room for all these frameworks [1]. However, Inayatullah draws on different sources, including Indian philosophical thought, poststructuralism and the work of Michel Foucault [1, 11, 12, 13]. One of Inayatullah's most valuable contributions to futures work has been the development of a new futures method, called causal layered analysis (CLA), which seeks to draw out different levels of reality and ways of knowing [12]. This method has been widely applied by futurists focusing on diverse content areas [13].

In this paper, I explore the theoretical and conceptual differences between Integral Futures work and CLA. My objective is to determine whether the theory behind CLA is consistent with Integral Theory and how CLA relates to Integral Futures work. I will consider whether CLA is an Integral method in its own right or needs to be complemented by other methods within the broader framework of IMP. Section 2 provides a summary of the theory and practice of CLA as a starting point for the discussion.

\section{CLA: theory and practice}

Causal layered analysis is a futures theory and method developed by Sohail Inayatullah. Inspired by poststructural and critical thought, particularly the work of Foucault, CLA 'takes as its starting point the assumption that there are different levels of reality and ways of knowing' [12]. Inayatullah defines four such levels of relevance to futures work. The first, or shallowest, is the litany, which is the official public or media description of an issue. Descriptions at the level of the litany focus on quantitative trends and problems. Explanations tend to be visible and obvious and issues are presented as unconnected, engendering feelings of helplessness and apathy [14, pp. 1112].

The second level 'is concerned with systemic causes, including social, technological, economic, environmental, political and historical factors' [14, p. 12]. ${ }^{1}$ It provides interpretation based on quantitative data, technical explanations and academic analysis. Good work at this level analyses the actions that precipitate an issue and explores the roles of various actors. However, while assumptions may be questioned, the paradigm within which a problem is framed remains unquestioned [14, p. 12].

The third level 'is concerned with structure and the discourse/worldview that supports and legitimates it' [12, p. 820]. ${ }^{2}$ As Inayatullah puts it:

\footnotetext{
The task is to find deeper social, linguistic, and cultural processes that are actor-invariant (not dependent on who the actors are) and to some extent system-invariant. Discerning deeper assumptions behind the issue is crucial here, as are efforts to re-vision the problem. At this stage, one can explore how different discourses...do more than cause or mediate the issue, but constitute it [14, p. 12].
}

Within this level, Inayatullah identifies four sub-levels at which discourse may be analysed, depending on the situation: stakeholder interests; ideological positions (e.g. Economism versus Sustainability versus Neo-Marxism); civilizational worldviews (e.g.

\footnotetext{
${ }^{1}$ My italics.

2 My italics.
} 
Western, Islamic and Confucian); and the epistemic (e.g. postmodern, modern and premodern) [14, p. 12].

The fourth and deepest layer is concerned with metaphor and myth, focusing on 'the deep stories, the collective archetypes, the unconscious dimensions of the problem or the paradox' [12, p. 820]. At this level: 'The language used is less specific, more concerned with evoking visual images, with touching the heart instead of reading the head' [14, p. 13]. The intent is to draw out and deconstruct conventional metaphors, articulate alternative metaphors and bring the unconscious and the mythic to futures work.

CLA can be used to guide theoretical research or in the more practice-oriented context of a futures workshop, where the focus is on action learning [14]. By moving up and down the layers, practitioners of CLA seek to challenge assumptions and create transformative spaces that can support new types of thinking about the future and lead to more effective policies and actions. The layered understanding of reality at the heart of CLA provides a basis for managing information, making it of great value for achieving convergence once a workshop has developed a lot of divergent information about possible futures. Scenarios can be used to provide horizontal breadth at any of the levels of CLA. In practice, CLA has proven to be of great value for drawing out the deep cultural commitments, worldviews, metaphors and myths that shape the way people interpret their world.

Inayatullah presents CLA as a theory and method that 'seeks to integrate empiricist, interpretive, critical, and action learning modes of knowing' [14, p. 1]. This integrative orientation makes CLA of definite interest for the emerging field of Integral Futures work. However, it remains unclear how the theoretical and methodological orientation of CLA compares to that of Ken Wilber's Integral Theory, the guiding framework for Integral Futures work. In Section 3, I will identify conceptual differences between Integral Theory and CLA to clear the way for future application of CLA within an Integral framework.

\section{An Integral interpretation of CLA}

As noted earlier, Integral Futures work draws on the work of Ken Wilber [8, 9, 10] and its interpretation for the futures realm by Richard Slaugher [2, 4, 5, 6, 7]. In this paper, I will focus on three key concepts from Wilber's broader epistemological and theoretical framework: quadrants, developmental levels and developmental lines.

\subsection{A summary of integral concepts}

Integral Theory contends that reality is composed of holons, or wholes that are parts of other wholes. All holons, from atoms to animals to humans, have both an objective exterior expression (e.g. body) and some form of subjective interior experience (e.g. feelings). At the same time, all holons are both whole individuals and parts of a collective [8]. These twin distinctions between the exterior and interior, and the individual and collective, give rise to four native perspectives, or ways of knowing, represented by the quadrants in Figure 1:

- Behavioral quadrant (Upper Right in Figure 1): an exterior perspective on individual holons, revealing the structure and actions of organisms 
- $\quad$ Systemic quadrant (Lower Right in Figure 1): an exterior perspective on collective holons, revealing the shared structure and actions of systems

- Psychological quadrant (Upper Left in Figure 1): the interior perspective of individual holons, which is the realm of the self, consciousness, personal experiences and values

- Cultural quadrant (Lower Left in Figure 1): the interior perspective of collective holons, which is the realm of shared discourses, worldviews, metaphors and symbols.

\section{[Figure 1 to appear hereabouts].}

Integral Theory also contends that holons develop holarchically, giving rise to recognisable stages, or levels, that transcend and include the previous levels. This holarchic development is evident in all quadrants. For example, Piaget showed that cognitive development (psychological quadrant) moves through sensorimotor, preoperational, concrete operational and formal operational stages [15]. However, Integral Theory does not conceive of development as a simple linear progression through levels. Rather, development is understood as a fluid process that occurs along many, relatively independent developmental lines, at varying rates. Developmental lines are distinct categories of development, or distinct holarchies, identified by developmental theorists and practitioners. For example, in the psychological quadrant, a sample of the recognised developmental lines includes 'morals, affects, self-identity, psychosexuality, cognition, ideas of the good, role taking, socio-emotional capacity, creativity [and] altruism’ [9, p. 28].

From an Integral perspective, an approach is comprehensive if it includes, at least, all quadrants, all levels and all lines. This kind of approach is summarised as all-quadrant, all-level (AQAL).

\subsection{Notions of depth in CLA and Integral Theory}

Integral Theory and CLA can both be characterised as responses to the failings of postmodernism. In his preface to Sex, Ecology, Spirituality, Wilber describes Integral Theory as a response to the unconstrained 'pluralistic relativism' of postmodernism [8, p. xi]. Postmodernists recognised that there are plural perspectives but argued that all of these perspectives are equally valid. Unfortunately, this argument ignores what is known about the development of the self and culture. Developmental research indicates that psychological and cultural development brings forth perspectives that are more inclusive than those that they transcend. Thus, for example, the postmodern recognition of plural perspectives is only possible after a long process of personal development, supported by cultural development. Like postmodernism, Integral Theory seeks to honour all perspectives; unlike postmodernism, Integral Theory also recognises that perspectives that emerge later in the developmental process have greater depth and a greater degree of consciousness than those perspectives out of which they emerge.

Similarly, CLA grew out of Inayatullah's sense that the postmodern recognition of plural perspectives was valuable but inadequate for futures work: 
Alternative futures and alternative renderings of reality are useful in opening the straitjacket of modernity, but only place research in the relativism of postmodernism - every frame is equally valued [14, p. 4].

Inayatullah sought to avoid the relativism of postmodernism by adopting a 'notion of reality as vertically constructed' [14, p. 4]. He drew this understanding of reality from Indian philosophical thought, in particular the Vedanta conception of the mind as constituted of five shells, sheaths or kosas. As Inayatullah puts it:

Moving up and down the shells is a process of moral and spiritual enlightenment. Going deeper into the mind is an inward process through which truths are realised [14, p. 5].

Up to this point, Integral Theory and CLA are closely aligned. Both understand development as a process that brings greater depth and both use depth as the basis for judging which perspectives are more valid. Although Integral Theory tends to present development as a process of growing to 'higher' levels and CLA tends to present development as a process of moving within to 'deeper' levels, these are metaphorical differences rather than true conceptual differences [9, pp. 110-111]. In fact, in Integral Pyschology [9], Wilber explicitly correlates the sheaths in Vedanta with the levels of consciousness in the Integral system. The five sheaths correspond to the material level (anna-mayakosha), the biological or emotional-sexual level (prana-mayakosha), the mental level or logical mind (mano-mayakosha), the higher mental or psychic mind (vijnana-mayakosha) and the spiritual or bliss mind (ananda-mayakosha) [9, p. 200].

Although Inayatullah is inspired by Vedanta, he does not use the five sheaths as the basis for the layers in CLA. From Vedanta, he takes the idea that reality is layered and the related idea that truths are revealed by digging beneath the surface. However, the layers he identifies are inspired by other sources, including Slaughter's division of futures studies into popular futures, problem-solving and epistemological futures [14, p. 5]. It is here that the theory of CLA departs from Integral Theory. The four layers identified by Inayatullah (the litany, systemic causes, discourse/worldview and myth/metaphor) do not correspond to the levels identified in Integral Theory. Rather, they include a mix of what Integral Theory defines as quadrants, levels and lines.

Consider the first two layers of CLA: the litany and systemic causes. Both tend to focus on quantitative data and problems, but the second level adds interpretation, technical explanations and academic analysis of economic, social, political and historical factors. In Integral terms, I would argue that both layers are concerned with exterior or quantitative realities (i.e. the behavioural and systemic quadrants) and marginalise important interior realities (i.e. the psychological and cultural quadrants). However, analysis at the second layer provides a more adequate description of these realities, emanating from a higher level of cognitive development (e.g. an analysis drawing on systemic cognition rather than one drawing on formal operational cognition). In other words, the first two layers of CLA both focus on the exterior quadrants but emanate from different levels of consciousness.

The third layer of CLA is concerned with structure, discourse and worldview. Inayatullah argues that the third layer provides deeper analysis than the first two layers. While this may be true, the Integral framework indicates that the more important difference between this layer and the first two layers is a shift of perspective from the exterior quadrants to the cultural quadrant. Discourse and worldview are two developmental lines in the cultural quadrant through which Integral Theory traces the 
development of cultural structures. Inayatullah also considers stakeholder interests, ideology and epistemes as components of this layer; all of these cultural structures can be understood as distinct but related developmental lines within an Integral framework.

As an example, cultural theorists have identified fatalist, hierarchical, individualistic and egalitarian discourses in the context of climate policy [16]. Although not drawn out by the original authors, a key characteristic that distinguishes these discourses from each other is their degree of concern for, and inclusion of ,other people [17]. Fatalists are concerned predominantly with their individual well-being, hierarchists with the well-being of their immediate social group, individualists with the well-being of all rational people and egalitarians with the well-being of all people without exception. Integral theorists have shown that the emergence of a greater degree of inclusion in cultural discourses, like these ones, is the result of a long process of cultural development over the course of human history $[8,18]$. From an Integral perspective, discourses, worldviews, group interests, ideologies and epistemes all constitute developmental lines in the cultural quadrant.

The fourth layer of CLA is the level of myth and metaphor. Again, from an Integral perspective, myth and metaphor are understood as developmental lines within the cultural quadrant. Like discourse and worldview, myths and metaphors are cultural elements that develop over time to achieve greater depth and a greater degree of inclusion. For example, where individualists tend to employ mechanical metaphors that exclude non-humans, egalitarians tend to employ ecological metaphors that are inclusive of non-humans.

An important additional point about these last two layers of CLA is that they are only available once a particular level of consciousness is reached. The ability to reflect on the discourses in which one is embedded and the myths to which one subscribes is not available to all people. It can only emerge after a long process of individual development: from egocentric or pre-conventional stages in which the main concern is with the self; to sociocentric or conventional stages in which the individual identifies closely and uncritically with their society; to worldcentric or post-conventional stages in which the individual is able to differentiate from and reflect on their society [10]. Thus, in applying CLA, we need to recognise that some of the participants in a CLA workshop may be unable to step outside their identification with a particular discourse, worldview, myth or metaphor, even with assistance.

Table 1 summarises the apparent correlations between the layers of CLA and the quadrants, levels and lines of Integral Theory. There is nothing inherently wrong with the tendency of CLA to move between quadrants, lines and levels; the valuable results it has achieved are evidence of this. However, the Integral framework allows us to identify where CLA might be located compared to other futures methods and what might be missed when CLA is applied alone. These issues are the focus of the next two sections. 


\begin{tabular}{|c|c|c|c|}
\hline Layer (CLA) & Quadrants & Lines & Levels \\
\hline The litany & $\begin{array}{l}\text { Behavioural } \\
\text { Systemic }\end{array}$ & $\begin{array}{l}\text { Multiple lines } \\
\text { considered in the } \\
\text { content (e.g. } \\
\text { population, } \\
\text { consumption, } \\
\text { technology trends) }\end{array}$ & $\begin{array}{l}\text { Analysis emanates from } \\
\text { average to below-average } \\
\text { levels of consciousness } \\
\text { (e.g. concrete operational } \\
\text { to formal operational } \\
\text { cognition) }\end{array}$ \\
\hline Systemic causes & $\begin{array}{l}\text { Behavioural } \\
\text { Systemic } \\
\text { (mainly) }\end{array}$ & $\begin{array}{l}\text { Multiple lines } \\
\text { considered in the } \\
\text { content (e.g. social, } \\
\text { technological, } \\
\text { economic, } \\
\text { ecological, political } \\
\text { developments) }\end{array}$ & $\begin{array}{l}\text { Analysis emanates from } \\
\text { average to above-average } \\
\text { levels of consciousness } \\
\text { (e.g. formal operational to } \\
\text { systemic cognition) }\end{array}$ \\
\hline Discourse/worldview & Cultural & $\begin{array}{l}\text { Discourse } \\
\text { Worldview } \\
\text { Stakeholder interests } \\
\text { Ideology } \\
\text { Episteme }\end{array}$ & $\begin{array}{l}\text { Discourse and episteme } \\
\text { are concepts that emerged } \\
\text { from postmodernism and } \\
\text { a postmodern level of } \\
\text { consciousness may be } \\
\text { required to fully } \\
\text { understand and employ } \\
\text { these concepts }\end{array}$ \\
\hline Myth/metaphor & Cultural & $\begin{array}{l}\text { Myth } \\
\text { Metaphor } \\
\text { Symbols }\end{array}$ & $\begin{array}{l}\text { While there are myths, } \\
\text { metaphors at all levels of } \\
\text { consciousness, it is only } \\
\text { at post-conventional } \\
\text { levels that one is able to } \\
\text { reflect on and compare } \\
\text { these myths and } \\
\text { metaphors }\end{array}$ \\
\hline
\end{tabular}

Table 1: An Integral interpretation of the four layers in causal layered analysis. 


\subsection{Favouring cultural explanations}

While Inayatullah is careful to stress that 'all levels are required and needed for fulfilling - valid and transformative - research' [14, p. 2] he also states that 'CLA does place a "higher” value on depth' [14, p. 11]. In CLA, the layers of discourse/worldview and metaphor/myth are conceived as deeper than the litany and systemic causes. Given the correlations identified in Section 3.2, this means that CLA favours cultural explanations over behavioural and systemic explanations; cultural analysis is seen as more powerful than behavioural or systemic analysis.

Here, CLA comes into conflict with Integral Theory, which contends that perspectives from all quadrants are required for a comprehensive approach. Behavioural, systemic, psychological and cultural analyses are all equally valid and equally valuable, within the boundaries of the quadrants to which they refer. Thus, if we are interested in the futures of climate change response (for example), we should give equal attention to empirical trends in greenhouse gas emissions (behavioural quadrant), the development of low carbon techno-economic systems (systemic quadrant), individual values around energy consumption (psychological quadrant) and the discourses that resist climate change response (cultural quadrant). None of these types of analysis is inherently more powerful than the others - all reveal important aspects of an evolving problem.

Wilber refers to the tendency to favour explanations from one quadrant over those from another as 'quadrant absolutism'. The cultural quadrant absolutism that is evident in CLA has two apparent sources. First, it should be noted that Inayatullah drew heavily on poststructuralism in his development of CLA [12]. The poststructuralists (e.g. Jacques Derrida and Michel Foucault) denied the existence of the subject, and of universal structures, emphasising instead the central role of cultural context in the construction of truth, meaning, knowledge and reality. By cutting loose from objective reality and killing the subject, poststructuralism committed its own form of cultural quadrant absolutism. It is not surprising that this preference for cultural explanations carries over into CLA.

In defence of poststructuralism, the emphasis on cultural context was a genuine attempt to draw attention to the cultural quadrant, which had been neglected and marginalised over the course of modernity. This leads to the second source of quadrant absolutism in CLA. Despite the efforts of postmodernists and poststructuralists, Western civilisation still focuses predominantly on the exterior reality revealed by rational scientific methods and either ignores interior reality (the psychological and cultural quadrants) or reduces it to its exterior correlates in the behavioural and systemic quadrants. Wilber [8, pp. 419-477] calls the resulting world 'flatland' - a world of surfaces, without any depth or meaning. Inayatullah's focus on the cultural quadrant, and conception of this quadrant as deeply buried, can be seen as a response to this flatland world. In the shortterm, it may well be necessary to over-emphasise cultural explanations as a way of overcoming the current marginalisation of cultural concerns.

It is important to note here that there is a sense in which cultural explanations are deeper than empirical explanations. As the ability to recognise plural perspectives and contexts develops after the ability to apply rational, empirical practices, those who are genuinely reflecting on multiple discourses, worldviews, myths and metaphors will often be operating from a deeper level of consciousness than those who are only able to 
apply rational cognition. However, it is not the focus on culture that makes this analysis deeper; it is quite possible to have superficial analysis of the cultural quadrant as well. Instead, it is the development of the practitioner that gives the analysis its depth. All types of analysis, across the quadrants, will offer deeper explanations when applied by practitioners operating from higher levels of consciousness.

\subsection{The exclusion of the individual subject}

In keeping with its poststructural roots, CLA gives little attention to the individual subject (i.e. the psychological quadrant). Poststructuralists saw the subject as socially and culturally constructed and moved on to focus on this social and cultural context. One of the key problems with this approach is that most people do understand themselves as subjects, with perceptions, values and other types of self-knowledge. This self-knowledge cannot be ignored in a comprehensive approach to reality, as called for by Integral Theory. The psychological quadrant is concerned with this self-knowledge, or knowledge of the individual interior.

In most applications of CLA, where collective futures are of primary interest, the lack of attention to the psychological quadrant is unlikely to be problematic. Discourses, worldviews, metaphors and myths operate as collective correlates and aggregates of individual values and perceptions and these collective structures will usually be more influential in shaping futures. However, there are two ways in which the exclusion of the individual subject may become problematic for an application of CLA. The first is when CLA is applied to a problem in which individual personalities are important. This might be a small-scale, local problem that is as much about the interactions between individuals (and their values) as any wider discourses in which they participate. Alternatively, it might be a larger-scale problem where a powerful individual has a pivotal role in determining future developments. In either case, understanding the complex value systems of the individuals involved is critical to move towards resolution of the problem or mapping of possible futures. For example, if a key politician is resisting the development of an effective climate change response, it may have much to do with their individual perception of the problem and the history of their personal experience and development. Although some of this individual psychology will be revealed through the discourses they share with their political party and constituents, much may remain hidden without individual analysis.

The second way that the exclusion of the individual subject may become problematic for CLA is when the participants in a CLA workshop are not developmentally equipped to reflect on their deep worldview commitments. As noted earlier, the ability to reflect on one's cultural context is associated with a post-conventional or worldcentric level of consciousness. A workshop participant that has not yet developed this capacity may find it difficult to grasp the idea that their perspective is not shared. When the CLA practitioner draws out different worldviews, discourses, myths and metaphors, the participant may feel antagonistic towards positions they do not share and will certainly find it difficult to inhabit or feel empathy for some of those alternative positions. In rare cases, the experience will be transformative for the participant, assisting their ongoing development. In most cases, the experience will either frustrate or leave no lasting impression. Some of the criticisms levelled at CLA (e.g. that it is ethereal, impractical, too critical or too difficult) [19] may originate from participants or practitioners that have become frustrated in this way. 


\section{CLA and integral methodological pluralism}

There is no doubt that CLA is a useful method that has made valuable contributions to futures work. However, the discussion in Section 3 demonstrates that CLA, applied alone, is not an Integral method. While it usefully draws attention to the neglected cultural quadrant, it does not delve deeply enough into the behavioural and systemic quadrants and neglects almost entirely the psychological quadrant. Consequently, both Inayatullah [14, p. 45] and Slaughter [6] define CLA as a cultural quadrant method within the broader Integral framework. I concur with this assessment - from an Integral perspective, CLA is primarily a method for exploring cultural perspectives, albeit a method that is more sensitive than most to behavioural and systemic realities.

In recent work, Wilber [20] develops an approach called integral methodological pluralism to guide the inclusion of multiple methods within an Integral framework. The approach has three principles: nonexclusion, unfoldment and enactment. Below, I will consider the implications of each principle for the role of CLA within a broader IMP.

First, the principle of nonexclusion tells us that CLA should be included as a valid method within IMP as long as it is applied in ways that are accepted by the peer community applying the method and as long as it does not seek to make claims outside the quadrants and levels from which it generates knowledge. Thus CLA makes its major contributions in the cultural quadrant, with some contributions in the behavioural and systemic quadrants, and few contributions in the psychological quadrant.

Second, the principle of unfoldment provides a reminder that perspectives develop over time and all methods will eventually be overtaken by paradigms that are more adequate and more inclusive. As a relatively new method, CLA may have a particularly important part to play at this point in the development of futures work as a way of drawing out discourses, worldviews, myths and metaphors in the cultural quadrant. However, once the cultural quadrant begins to receive regular attention, CLA may be superseded by methods that are more adequate to the new understanding of reality.

Finally, the principle of enactment draws attention to the role of the CLA practitioner and participants in enacting the method. The results achieved by CLA will depend on the behavioural, systemic, psychological and cultural context and the developmental levels of the participants. While the main value of CLA within an Integral framework is to draw out aspects of the cultural quadrant, the results will be of more value if the participants are aware of the interactions between the cultural quadrant and other quadrants. Ideally, when CLA is applied within an Integral framework it would be applied alongside other methods that focus more strongly on developments in the behavioural, systemic and psychological quadrants. One of the great strengths of CLA for Integral futures work is that it is already open to the inclusion of behavioural and systemic concerns alongside cultural concerns.

\section{Integral CLA}

Given that CLA is a valuable futures method that has a clear role within an Integral framework, is there any value in trying to extend CLA into an Integral method in its own right? I think there is potential to develop a more Integral CLA that retains most of the key characteristics of the current conception of CLA. Below, I present some initial ideas for a more Integral form of CLA. 
An Integral CLA would need to attend equally to all quadrants and levels. This means abandoning the idea that discourse, worldview, myth and metaphor represent deeper realities than the various structures in the behavioural, systemic and psychological quadrants. The layered conception of reality is retained; however, layers would need to be redefined to coincide with the developmental levels identified in each quadrant. Instead of moving up and down four layers, Integral CLA would need to move across four quadrants and up and down multiple levels in each quadrant. The number of levels that would need to be considered would depend on the application. In many applications, three levels could suffice (e.g. pre-conventional, conventional and postconventional, or mythic, modern and postmodern). In other applications, it could be valuable to use a more complete conception of levels, such as the eight stages of consciousness defined by Wilber [21].

Scenarios could be developed within and across levels to explore various dimensions of a problem. They provide a way of creatively drawing out differences across levels - not only cultural differences but behavioural, systemic and psychological differences. An advantage of this Integral version of CLA would be the ability to judge which scenarios are preferable. Currently, the lack of an explicit developmental perspective in CLA makes it difficult to judge which worldviews, discourses, myths, metaphors and scenarios are preferable; in an Integral CLA, these judgements can be made on the basis of the degree of development and inclusion.

I can think of two possible ways to apply an Integral CLA. With a group of Integrallyaware participants, it could be used to dig down through the levels in each quadrant to understand how reality feels and looks at each level. This understanding could then be used to design policies, actions and strategies that are sensitive to multiple levels.

Alternatively, an Integrally-aware practitioner could use the method to deepen their own understanding of each of the levels, providing a basis for translation of concepts to workshop participants who are not Integrally-aware. This would address the problem discussed in Section 3.4 of participants not having the developmental capacity to reflect on multiple values, discourses or levels of reality. The onus would be on the practitioner to identify the capacities of the participants and to communicate in terms that they are comfortable with. This approach would clearly be very demanding for the practitioner. However, because it meets people where they are, it is an approach that is more likely to resonate with the participants.

With these modifications and extensions, it is possible that CLA could be employed as an Integral method in its own right. However, as with CLA in its present form, the method will need to develop over time within an action learning framework. These initial ideas may prove unworkable in practice, or lead to new insights.

\section{Conclusion}

In this paper, I have used the Integral framework to develop a critique of causal layered analysis. The purpose of the critique is not to question the value of the method but to clarify some conceptual differences as a way of clearing the path for the application of CLA as part of Integral futures work. From an Integral perspective, the main criticisms of CLA are that it favours the cultural quadrant, neglects the psychological quadrant and generally confuses quadrants, developmental levels and developmental lines in its layered conception of reality. Further, an Integral perspective draws attention to the possibility that some of the participants in a CLA workshop may not have developed the 
capacity to reflect on their society, discourse or worldview. This constitutes a barrier to successful application of the method.

Nevertheless, in the right circumstances and with a degree of sensitivity to each of the quadrants, CLA can be successfully applied in an Integral framework. Its role would be to draw out deep cultural commitments alongside other methods that focus on the behavioural, systemic and psychological quadrants. Further, there would seem to be potential to develop a more Integral CLA that digs down through the levels in each quadrant to deepen understanding of how reality looks and feels at each level. Clearly, CLA is a valuable method for Integral futures work, particularly at a time when cultural perspectives continue to be marginalised in Western civilisation.

\section{References}

[1] S. Inayatullah, Deconstructing and Reconstructing the Future: Predictive, Cultural and Critical Epistemologies, Futures 22 (2) (1990) 115-141.

[2] R.A. Slaughter, Futures Beyond Dystopia: Creating Social Foresight, RoutledgeFalmer, London and New York, 2004.

[3] R.A. Slaughter, Critical Futures Studies and Curriculum Renewal, PhD thesis, University of Lancaster, 1982.

[4] R.A. Slaughter, Transcending Flatland: Implications of Ken Wilber's Meta-narrative for Futures Studies, Futures 30 (6) (1998) 519-533.

[5] R.A. Slaughter, Futures Beyond Dystopia, Futures 30 (10) (1998) 993-1002.

[6] R.A. Slaughter, Knowledge Creation, Futures Methodologies and the Integral Agenda, Foresight 3 (5) (2002) 407-418.

[7] R.A. Slaughter, Beyond the Mundane: Reconciling Breadth and Depth in Futures Enquiry, Futures 34 (6) (2002) 493-507.

[8] K. Wilber, Sex, Ecology, Spirituality: The Spirit of Evolution, 2nd ed., Shambhala Publications, Boston, 2000.

[9] K. Wilber, Integral Psychology: Consciousness, Spirit, Psychology, Therapy, Shambhala Publications, Boston \& London, 2000.

[10] K. Wilber, A Theory of Everything: An Integral Vision for Business, Politics, Science and Spirituality, Shambhala Publications, Boston, 2001.

[11] S. Inayatullah, From Who am I? to When am I?: Framing the Shape and Time of the Future, Futures 25 (3) (1993) 235-253.

[12] S. Inayatullah, Causal Layered Analysis: Poststructuralism as Method, Futures 30 (8) (1998) 815829.

[13] S. Inayatullah (Ed.), The Causal Layered Analysis Reader: Theory and Case Studies of an Integrative and Transformative Methodology, Tamkang University Press, Taipei, 2004.

[14] S. Inayatullah, Causal Layered Analysis: Theory, Historical Context, and Case Studies, in: S. Inayatullah (Ed.), The Causal Layered Analysis Reader, Tamkang University Press, Taipei, 2004, pp. 152.

[15] J. Piaget, The Child's Conception of the World, Granada, London, [1929] 1973. 
[16] M. Thompson, S. Rayner, Cultural Discourses, in: S. Rayner \& E.L. Malone (Eds.), Human Choice and Climate Change, Volume One: The Societal Framework, Battelle Press, Columbus, Ohio, 1998, pp. 265-343.

[17] C. Riedy, The Eye of the Storm: An Integral Perspective on Sustainable Development and Climate Change Response, PhD thesis, University of Technology, Sydney, 2005.

[18] J. Habermas, Communication and the Evolution of Society, Beacon Press, Boston, 1979.

[19] S. Inayatullah, Responding to the Critics, in: S. Inayatullah (Ed.), The Causal Layered Analysis Reader, Tamkang University Press, Taipei, 2004, pp. 527-534.

[20] K. Wilber, Kosmic Karma and Creativity, Excerpt B: The Many Ways We Touch - Three Principles Helpful for Any Integrative Approach, Shambhala Publications, viewed 11 November 2003 $<$ http://wilber.shambhala.com/html/books/kosmos/excerptB/intro.cfm/>.

[21] K. Wilber, Integral Spirituality: A Startling New Role for Religion in the Modern and Postmodern World, Shambhala, Boston, in press. 


\section{Author details}

Dr Chris Riedy (criedy@uts.edu.au) is a Research Principal at the Institute for Sustainable Futures, University of Technology, Sydney, with ten years experience as a researcher and consultant investigating the economic, social, political and cultural dimensions of sustainable development. His $2005 \mathrm{PhD}$ thesis used the Integral framework to explore behavioural, systemic, cultural, psychological and developmental perspectives on energy and greenhouse policy in Australia.

\section{Figures (captions)}

Figure 1: The quadrants in Integral Theory. 